\title{
Contraceptive Use Related Health Benefits as Women's Experiences Explored Phenomenologicaly in the Rural Part of Southern Ethiopia
}

\author{
Alano Abraham \\ School of Public and Environmental Health, School of Nursing and Midwifery, Hawassa University, Hawassa, Ethiopia \\ Email address: \\ alanoabraham@yahoo.com \\ To cite this article: \\ Alano Abraham. Contraceptive Use Related Health Benefits as Women's Experiences Explored Phenomenologicaly in the Rural Part of \\ Southern Ethiopia. Central African Journal of Public Health. Vol. 5, No. 2, 2019, pp. 83-91. doi: 10.11648/j.cajph.20190502.14
}

Received: January 11, 2019; Accepted: February 19, 2019; Published: March 14, 2019

\begin{abstract}
Despite the existence of notable remedies for maternal and child health, mothers and children in developing nations are affected disproportionately. Contraceptive service has been contributing for the betterment of maternal and child health by averting unwanted and unplanned pregnancies. However, the effect is not uniform across the nation and the globe. This study is conducted with the purpose of exploring the experiences of current contraceptive users and cascade to the nonusers to enhance the benefits of contraceptive use for maternal and child health. The study employed an interpretive phenomenology to explore the lived experiences of current user. Focus group discussions and individual in-depth interview methods used to collect information. Data were analyzed using interpretive phenomenological analysis. The finding indicates that contraceptive use has created great changes both in the lives of mothers and children when compared to the non-use period. They acclaimed that they got time to care for themselves and their children by averting unplanned pregnancies. Based on the study finding it is concluded that women are able to control their body, their fertility and hence relieved from the trap of unplanned pregnancies. The experiences of the current user women can be best lesson for the non-user, hence, further improve the health status of mothers and children in rural part of the country.
\end{abstract}

Keywords: Contraception, Health, Phenomenology, Lived Experiences, Mothers and Children

\section{Introduction}

Maternal and child health programs are together treated as one of the priority health programs in most countries. They are frequently coupled, because mothers and children have closely related health outcomes [1]. They are prioritized because their numbers contribute to about two-thirds of the total population of most nations. However, both maternal and child health outcomes negatively impacted in most developing nations [2]. It has been realized that high maternal mortality is associated with high pregnancy rates, childbirth complications in older and younger women, and abortion. It is reported that globally, forty one percent of pregnancies are unwanted, with twenty two percent resulting in induced abortion [3]. Child health, in similar manner, is affected due to many factors among which closely spaced pregnancies and child births receive significant proportion [2].
Among the wonderful medical innovations for the betterment of maternal and child health, modern contraceptive methods can be sited on the top [4]. In the last fifty to sixty years, there have been a number of rationales and related benefits advanced by global agencies for the use of contraceptives, which were frequently adopted by national health systems in their own campaigns [5].

A health-based rationale for contraceptive use supports the assertion that contraceptives contribute to the improvement of the health of mothers, children, and to the entire family through averting unwanted and unplanned pregnancies and unsafe abortions [5]. Having numerous and frequent pregnancies adversely affects the health and wellbeing of mothers and babies, and overstretches the household workload and national economy [6].

Contraceptive use protects women and infants from the medical risks of pregnancy, delivery, and the postpartum period. In particular, those risks associated with unplanned 
pregnancies, closely spaced pregnancies, or pregnancies among women who are very young are alleviated [7]. A third to two-fifths of maternal deaths could be avoided if unplanned and unwanted pregnancies among sexually active women were prevented through contraceptive use [8].

Studies indicated that globally, about ninety percent of abortion-related and twenty percent of obstetric-related mortalities and morbidities could have been averted by use of effective contraception [9]. If countries with high birth rates promote appropriate family planning measures, thirty- two percent of maternal and ten percent of child deaths can be averted [10]. A systematic world-wide study has indicated that for each month fewer than 18 months lapsed between pregnancies, the likelihood of low birth weight increases by three percent, while having a premature birth increases by two percent [11]. Similarly, the elimination of closely spaced births, defined as those occurring less than two years apart, would prevent about 1 million deaths of children aged under years, out of 11 million such deaths each year [12].

Within the context of Ethiopia, contraceptive service provision was started with the intention of addressing the issue of population growth and economic development, and maternal and children health [13]. Evidence indicates that if all unmet needs for family planning were met, 1.5 million unintended pregnancies, and one-third of maternal mortalities could have been averted. Even currently low levels of contraceptive use have contributed to the improvement of maternal health by averting 700,000 unwanted pregnancies and 188,000 induced abortions in a year in Ethiopia. As such, family planning has averted approximately 2,700 maternal deaths and prevented the loss of 240,000 healthy years from women's lives each year [14].

Despite some encouraging efforts and recent progress in improving access to reproductive health services, including contraceptive methods provision, Ethiopia remains challenged with wide gaps and lags in service provision to reach the desired level of contraceptive acceptance, fertility, and accompanying health benefits for women and children.

An important cue to addressing these challenges is that in similar socio-economic, cultural, and environmental contexts, some women appear to adopt modern contraceptives while others did not. This trend occurs in almost every part of the country where the contraceptive services are available [15]. Yet, there is little evidence that explains why. The evidence is also elusive regarding how family planning service provision enhances or discourages uptake for the rural population, particularly within the current health services delivery approach using the health extension program. Virtually no research to date has investigated these issues, particularly as perceived by the primary beneficiaries (the rural women).

The purpose of this study is to improve the understandings of contraceptive use and benefits as perceived by the women themselves, with the intent to ensure that the process and content of contraceptive programs contribute to the betterment of women's and their children's health. In addition, by sharing experiences of current users' perceptions regarding contraceptive benefits, the study aims to contribute to narrowing the gaps between current users and their counterparts - women with unmet needs - thus improving the understanding of factors contributing to sustained contraceptive use. Overall, the study seeks to assist in the reduction of maternal and child morbidity, mortality, and improved quality of life of women and children in Sidama Zone, South Nation and Nationalities and Peoples Region, in Ethiopia by informing the improvement of contraceptive health services provision.

\section{Materials and Methods}

\subsection{The Research Context}

This study was conducted in three districts of Sidama Zone. These three districts were selected conveniently among the six districts of Sidama zone which Hawassa University designated for its research and technology transfer. Hawassa University is situated in this administrative zone and revitalized its research and community services in order to visualize its contribution to the surrounding communities and ensure its transformation plan. Sidama Zone is one among the thirteen zones in the Southern Nations Nationalities and People's Regional Government (SNNPRG), under the Federal Democratic Government of Ethiopia. Sidama is located in the south-eastern part of the region and is bordered on the south, east and north by the Oromia Region on the west; it borders Wolaita Zone [16]. According to the population projection based on the 2007 national population census, the zone has a total of $3,471,568$ people of which 1,753, 142 (50.5 percent) are males and 1,718,426 (49.5 percent) are females. Women of reproductive age are estimated to be 23.8 percent of the total population. Household population size is estimated to be 4.7. Annual population increase is estimated to be 2.9 percent [17].

\subsection{Study Design}

The interpretive (hermeneutic) qualitative approach appropriately guided the study, as it focuses on describing the meaning of the individuals and how these meanings influence the choices they make, rather than seeking purely descriptive categories of the real, perceived world in narratives of the participants [18]. It further considers the importance of the expert knowledge of the researcher as a valuable guide to the enquiry. Exploring the lived experience related to contraceptive use by employing this approach clearly offered a unique opportunity to establish a rich and in-depth understanding about the contribution of contraceptives toward the empowerment of women, the improvement of the health of women and their children, and the society at large [19].

\subsubsection{Data Collection}

In order to broadly capture information related to the topic of interest, the study employed linguistically competent research assistants and utilized two main data collection methods: the focus group discussions (FGDs) and the 
individual in-depth interview. Research assistants were recruited based on their educational preparedness and research related experiences. After recruiting and training the research assistants, health extension workers and local women community leaders collaborated with them in a selection of study participants. A semi structured interview guide developed for the study encouraged participants to speak about their experiences and deepened discussion and reflection on their lived world [20, 21].

Focus group discussion explored the experiences and perceived benefits of contraceptive use of women of reproductive age in detail [18]. A total of nine FGDs were conducted from the three selected study districts and nine kebeles (health posts). Eighty-two women of reproductive age who satisfied the recruitment criteria were involved in 9 focus group discussion sessions. The number of participants in each session ranged from 7 to 12 .

Discussion and arrangements of dates was done with due consideration of the time and rhythm of rural women. All the discussions were done on non-market days and from 10:0011:30 AM. Women were contacted through the women community leaders and the health extension workers about the date, time and place of the discussion. We conducted the focus group discussions within the health post closer to study participants in a manner that all participants received equal attention to explore their lived experiences.

Follow up individual in-depth interviews were carried out with women who had been using contraceptives for longer duration (the minimum use time considered for this category was 18 months) $\mathrm{n}$ order to triangulate the findings. A total of 18 individual in-depth interviews were conducted. The research team conducted the interviews at either the residence of the women or at the health post depending on the preference of the interviewee. For those conducted in the home, the research team was guided to the house by either the health extension worker or community leader or both. A consent form was read and permission obtained to continue the interview and record the interview via audio-tape and taking down notes.

During the interviews, the researcher probed beyond each question based on the response of the participant. Moreover, the interviewee was encouraged to talk about her lived experiences in detail without any shyness or discomfort. The interview continued in such a way from 40 to 60 minutes until the study team felt that the ideas emerging appeared to repeat, suggesting saturation.

\subsubsection{Data Analysis}

This study used the guiding principles of interpretive phenomenological methodology to explore the lived experiences of women's' contraceptive service use and their perceptions of related benefits. The methodology also encouraged consideration of the experience of the researcher as a professional and member of the community; experience that offered an additional lens through which to view the data. Interpretive phenomenological analysis enabled viewing the phenomenon in such a way that considers the close interaction between the participants and researchers as instances of their 'being in the world" rather than only "being' itself $[22,23]$. In a sense, the final presentation of the data thus becomes an inter-subjective representation of the topic of the study. An adapted flow diagram from the interpretive phenomenological analysis (IPA) was used to guide the analysis.

The process of data transcription and analysis was made more complex due to three languages being involved. The following steps describe the process: Transcriptions were made of all the audio-taped materials verbatim, first from Sidamigna into Amharic and then to English. Materials were also translated back to Amharic by a linguistic professional. The Amharic translation was then given to the research assistant to translate back into Sidamigna, after which the document was reviewed for consistency. Study participants were given chance to see the transcribed data and summary results and made comments based on their impressions. Field notes were organized under the guiding research questions. Data immersion by the researcher has taken place by reading the transcripts several times. Repeatedly reading and rereading the material has revealed recurring ideas and concepts. In the data immersion process, several visits were made to the study participants as a first step in identifying descriptive codes and checking preliminary interpretations. The participants commented on some points following an initial description of the issue(s), and these were incorporated into the second round of data analysis with remarks. Margin notes and descriptive coding were then completed for all the materials. Data reduction was done in a step-by-step approach, beginning with the transcripts, followed by descriptive coding, and then distilling this material into themes by bringing similar ideas and concepts together.

Deriving themes was done with consideration of both emergent themes and the research questions. The analysis process made use of the idea of a hermeneutic circle; in brief, the back and forth iterative linking of data from both the perspective of both the researcher and study participants [24]. Summarized reports were presented to the study participants about the phenomena derived from their shared experiences. Discussions were held with participants about the study guide questions and core concepts of the study. Their feedback was then considered alongside the experiences of the researcher.

Quality assurance or trustworthiness of the results used four criteria- credibility (truth value), transferability (applicability), dependability (consistency), and conformability (neutrality) suggested in the literature [2526].

\subsection{Ethical Considerations}

We obtained ethical clearance from the University of Saskatchewan Research Ethical Review Board, Canada and Hawassa University Institutional Review Board, Ethiopia (evidences attached elsewhere). Through a verbal informed consent process facilitated by the research assistants in local language, we assured research participants rights to participate or withdraw from the study. Through follow up 
sessions, the researcher and research assistant assured that the information gathered during the study is kept confidential. The back and forth translation of transcripts were presented to the study participants after initial analysis summary in order to assure the correctness of the information they offered.

\subsection{Limitation and Delimitation}

The limitations of the study may be that it has considered only married women, and in only three districts. The sensitivity of the issue of contraceptive utilization may be one factor that limits the response during data collection. Another possible limitation is that the study hasn't considered current non-users' perception about the benefits of contraception.

The delimitation of this study is explicated in terms of the study purpose, the selection of study area and selection of study participants. The study was carried out with the intention to explore the experiences of women contraceptive service users in the Hawassa University research villages, which were established with the intention to observe the impact of university-based research in knowledge generation, technology transfer and the livelihood of the residents.

\section{Result}

Women's experiences of contraceptive use: health benefits

This study sought to learn the health related benefits of contraceptive use from the perception of the service users specifically, women in the rural community of Sidama, SNNPR, Ethiopia. Overall, women discussed the health related benefits by comparing their lives before and after the service use, and by comparing their lives with their mothers. Results clearly showed the multidimensional benefits of contraceptive use for both women and their children's health.

It was indicated that many factors have been affecting both women's and children's health. Women expressed their perceptions about their own health status before making use of contraceptive services. All study participants consensually expressed that their pre-contraceptive health status was poor in many ways. Women's modern health service use was hampered due to their ignorance and absence of services in their vicinities. Rural women were far from modern health information and services previously. Consequently, they were exposed to the risks posed by harmful traditional practitioners in their localities or would simply wait for illnesses to play themselves out naturally.

\subsection{Women's Life World Before Contraceptive Use}

A 25 year-old woman with five children who had used contraceptive services for three years put her precontraceptive use life like this:

Let me say something about my life before contraceptive use. I was forced to bear children very closely. I did not have enough to give for my children and I did not get proper food during my puerperal ${ }^{1}$ time. I was badly affected by chronic nutritional problems and no desire for life including sex. (FGD 01 Dis \# 8; P. 8, Para 3 line 1-4)

A 25 year-old woman with four children who had used contraceptive service for ten years added her experience as:

Before this service use our lives were full of fear and challenge. You know... we were thinking of subsequent pregnancy immediately after birth. We wished to abandon it but it was not possible as long as we live with our husbands/men. (FGD 01 Dis \# 2; P. 2, Para 2; line 1-3).

As has been elucidated, these women's lives were spent trapped between being pregnant and caring for very young children. They have experienced much child illness and death, and quite often death resulted for mothers due to problems in pregnancy and childbirth. As they bore children on a yearly basis, they did not have enough time and resources to properly care for their children.

A 36 year-old woman shared her experience by stating:

When I gave births every year basis, I had no time to breast feed, provide balanced food and overall care. The subsequent pregnancies took place close and deprive necessary care to the older one. Due to such conditions, the children born these ways got sick frequently. I was emaciated as giving births yearly basis and keeping on breast feeding. (FGD 07 Dis \#1).

A woman from the ninth FGD site similarly expressed her experience:

While I was unable to feed my first daughter in a critical situation, I got pregnant again suddenly in a year time. Thus, I was forced to stop breast feeding my first child despite her deep desire to continue it. She was crying very much when I prohibited her from breast feeding. My second child came soon after. (FGD 09 Dis \#5 p. 58, Par. 4, line 2-7)

Women's experiences regarding their personal care revealed that it had been highly undervalued, being unable to prioritize their own needs amongst so many competing factors amidst a lack of time and resources. As a result, they lived in unhygienic and poor conditions. Their time was almost always occupied by being pregnant and or caring for very young children. The excrement of young children and spoiled breast milk residue on their clothing caused unpleasant odours, and it seemed that they were unable to care for themselves or their bodies, jostled from one thing to another to accomplish day-long domestic responsibilities.

A 35 year-old woman has shared her experience by stating:

We were unaware of ourselves before we use contraceptive methods. We had no time to clean ourselves. We have no time to think for ourselves. We were untidy; our body smells foully, children urine was all over our rags and bodies. We start ramifying in the morning to prepare breakfast, and then engage into our daily routines such as preparing lunch, fetching water, gathering fodder for cattle, cleaning cattle waste etc. Our day goes as we were swinging here and there. (FGD 01 Dis \#1 p. 1 para. 1, line 1-5).

\footnotetext{
1 Puerperal is an equivalent term for the woman's expression 'aras/mechat' meaning the first forty five days after child birth.
} 
A 30 year in-depth interviewee woman from study site 03 added her experience with the same topic as:

If to put in a very simple way, before contraceptive service use, our lives were messy, untidy and full of bad odors. We were forced to pass our nights in bed richly soaked with children urine. (III \#7 P. 13, Para 7, line 1-3).

On top of all these and other challenges, these women experienced discord in their marital relations. Neither their husbands nor the surrounding society appreciates or sympathises with their burdens, but rather, disgraces them. Husbands easily move out looking for other wives who catch their eyes, as they no longer find their older wives attractive. These women are emaciated, untidy, weak, and overwhelmed with domestic duties and child care and as they state it, they have little time or will to please their husbands.

A thirty year-old uneducated woman from FGD site 03 expressed her experience in a similar manner:

When my husband married me, he had strong love. But when I started to give birth, he was keeping him distant from me. In past when I deliver, I was forced to stay away of our regular bed. Temporary bed is being prepared from the leaves of 'inset' 'hashuchcho' on ground. Due to baby's urine and uncleanliness, worms used to grow beneath us. (FGD 03 Dis \#6 P. 24, Para. 4, line 1-5)

In similar way a 22 year-old woman from FGD site 06 has given her insight as:

In the past when we were untidy and contaminated with our children's urine and faeces thus, people disgraced and undermined us. Even our husbands did not care about us. They too, undermine and down look us. We were trapped in burdens of domestic work including child care. Our lives were totally engulfed by pregnancy and child bearing. (FGD 06 Dis \# 3 P. 40, Para 3, line 1-4)

Closely spaced consecutive pregnancies and child births also depleted women of their nutritional reserves and deteriorated their overall health status. Women in the study have also experienced poor health in the past due to the inability to eat adequately and a lack of time to rest. Most of the time in rural communities, women's needs were subordinated to those of other family members in the house. They sadly expressed situations they experienced in the past, passing many nights with no or little food. Women were the last to eat, if they ate at all, after serving their husbands and children. Consequently, they were undernourished, sick looking, dizzy and desperate. They described totally disliking their lives and how they sometimes argued with their God, asking why "He" had created them to lead such miserable lives. They felt highly dissatisfied and angry about their fate and that of their children. Their previous life experiences showed that they preferred dying than seeing their children's suffering from malnutrition and frequent illness.

In connection to the above statements are the following points raised by a twenty-five year-old woman with seven children from FGD in site 03:

I had one difficult labour which had threatened my life. If I had not started contraceptive method use, I would have died this time due to pregnancy related problems. Thus, above all contraceptive has saved my life. During the difficult labour what I faced was retained palcenta. Nobody has taken me to health institution. The retained placenta expelled by itself the second day and bleed massively. That has clicked me to be on contraceptive for fear that subsequent pregnancy would carry more risk. I know similar incident which had ended in life loss. (FGD 03 Dis \# 4 P. 20 Para 4, Line 3-7)

Another area related to women's reproductive health is poor marital relations. They commonly experience quarrelsome nights with their husbands. When night fell, they hated it, as they knew the request of their husbands was coming. Some of them mentioned that they could hardly remember having had sexual relations with their husbands joyfully. They said that the sexual feelings of a person depend on how one's body is physically and psychologically prepared. When hungry and tired, how could they think of sex? Instead, what comes to her mind is what to give her children the next morning, and how to handle domestic duties in an orderly and timely manner. But their husbands' thinking was different than theirs. Women were not in position to deny their husbands' requests despite their deep disinterest.

A discussant in one of the FGDs put her experience this way:

However, my husband always urges me to have sex with him. When he comes to me I move out. I have no desire as my body was emaciated, from having no good food at that particular day. Men need women more than food for being women (sexual affairs). The reason is that after eating well he needs sex at night. If this fails to happen or I refuse to meet with him that night, he withholds the money to buy food for two to three days.

Another of the reasons why women disliked sexual relations with their husbands was the fear of becoming pregnant. They knew that they have not enough to serve older children and care for other family members, that and having more children would mean more challenges for them. However, their husbands were totally non- supportive of this concern and forced them to have even more children despite the consequences.

\subsection{After Contraceptive Use}

Study participants collectively expressed their positive feelings towards contraceptive benefits in relation to their health and that of their children. They clearly stipulated the benefits of contraceptive use to many dimensions of their lives. They said that the majority of problems discussed previously in this study have been resolved by the use of contraception. First and foremost, they joyfully expressed that they are able to plan pregnancy and postpone it to the time they want. They revealed that unplanned pregnancies have been the causes for the many maternal and child health problems described above. Planning their pregnancies allows the women adequate time to care for themselves and their children.

A twenty-five year-old woman with five children from FGD 04 expressed her experience:

After we used contraceptive methods, a woman spaced her 
pregnancies, maintained her cleanliness, put on fragrant ointments, cosmetics and perfume, eat well and built her body, has good mattress thus pass her time with her husband in bed properly. Now we understood why our men married to seven and more as the one in the house looked wildish, unattractive and skinny, as result swing their eyes to outsiders. Today we give time to ourselves and our husbands receive our contraceptives on time and avoided unwanted pregnancy, thereby we live peaceful and lovely lives. (FGD 04 Dis\#7 p. 31, para 2, line 3-8).

The women in the study also mentioned that from the time they started using contraceptive services, they became clean, hygienic and maintained their personal appearances. They have changed their image in the society from a previously untidy, foul-smelling state to one that is pleasant and attractive. Contraceptive service use has improved their knowledge of other health related issues such as vaccination, growth monitoring, HIV and AIDS, ANC, prevention of harmful traditional practices, etc. Their knowledge of other health services was improved through the integrated health service delivery approaches. When they visit the health post for contraceptive service, they also get information from the health extension workers about the other packages of the health extension program. Women also mentioned their ability to access health services in their nearby kebele. They said that at this time, every kebele has its own health post where women access health services such as contraceptive methods. As a result their health related knowledge has improved.

In connection to this, a young woman with four children from FGD site 05 gave her insight towards her experience:

Since the inception of contraceptive service use, we, women have been able to space pregnancies and delay childbirth. We keep our personal hygiene and that of our children. There is no as such foully smelling like the previous time and our husbands are not distancing themselves from us. Now the woman appears attractive and neat that a man is also motivated to have good sexual relation with her. We, the women also desire sex when we eat well and feel healthy. Contraceptive use has created golden chances for us to avoid undesired pregnancies; hence our body weight, makeup and appearance seem well. (FGD 05 Dis\#3 P. 37, para. 5, line 48).

A quotation from a woman from study site 06 affirms this account:

But, after the introduction of contraceptive services in our locality, women are able to bear children in spaced and planned manner. The older child was grown before the subsequent one comes. He/ she reached to the stage of walking, running and playing with neighbor children before their younger born. We have got adequate rest between pregnancies; the amount of bleeding during labour has become normalized. We feel healthy, stronger physically, and knowledgeable about various issues including reproductive health. While receiving contraceptive service we have also acquired better awareness and skills and how to care for our children in terms of complementary feeding, providing balanced diet from various sources, their hygiene. Both our mothers time and in our time before contraceptive service use, we had no exposure about proper children feeding practices. (FGD 06 Dis \# 2 P. 39, para 3, line 6-13.)

Because of an ability to plan pregnancy and control the time between pregnancies, the women who participated in this study reported eating relatively well and having improved physically. The changes in their physical health status are apparent in many ways. During the times in which they gave birth on a yearly basis and lacked enough to eat, they were highly emaciated. As a result, they considered themselves so light that even a wind could easily lift them up. Since using contraception and being able to space their pregnancies, they have had the chance to properly nourish themselves and now feel their weight to be standard. They expressed that when walking, they now put their legs down with enough force that they could hear the sound of their steps on the ground.

The women who participated in the study also stated that since they began to use contraceptive services, they feel free and peaceful psychologically. Contraceptive service use has alleviated their worries related to frequent pregnancies. They also considered themselves most fortunate to receive the service in order to control time between pregnancies. The women explained this sense of good fortune by comparing the quality of their lives before and after using contraceptive services. Contraceptive use has not only improved their health status, but averted premature maternal and child deaths. In connection to this, they explained how they had lost either their mothers or sisters due to problems related to unregulated pregnancies and child births. With these losses in mind, the women expressed how fortunate they are to see this bright day, and are able to enjoy the benefits of contraception.

A 25 year-old lady who used contraceptive service for four years, from FGD site 03 explained her lived experience of how she has benefited from the service:

I know of similar incident which had ended in life loss. My husband's sister was died in similar condition. They took her to Yirgalem hospital after long delay with retained placenta but on her arrival at hospital, she lost her life. You see, God has brought this service to avert such premature death of mothers. I really understand that we have got many benefits and averted maternal death that may occur as a result of unwanted pregnancies. (FGD 03 Dis \#4 P 20, para. 4, line the last 5 lines of the paragraph).

Study participants reported on the improvement of their children's health status following the mother's use of contraceptive services. Children born after service use are doing very well both in their physical growth and mental development. The mothers are now able to breast feed their children for at least for two years and are able to give them better care. The participants have recognized that when the number of children is a small or manageable size, and the proportions of shared food are adequate. The women mentioned children born after service use are stronger, and doing very well while playing, studying, and working. 
Moreover, it was expressed that they have established better bonding with their children as they have more time to spend with them.

A study participant from FGD 09 has elucidated her experience with regard to children health after contraceptive use in the following manner:

Children born after contraceptive use have got better care than their older brothers and sisters. The older children had frequently affected in many diseases. I took them to health institutions many times. The two children born after contraceptive use are healthier and stronger. They had never been affected by any noticeable disease. They have received recommended vaccinations and received certificate for their accomplishment from the health post. (FGD 09 Dis \# 1 P. 57. Para. 2, line: five lines from the end).

During pre-contraceptive use, women were forced to visit the health institution very frequently to seek medical help for sick children. Since using contraception, they only visit for vaccinations and growth monitoring. Their quarrel with their Lord has changed to thanks for what they have received. The reason is because they have seen that their children are growing very well, they have more time to care for them.

One discussant woman from FGD site 06 has clearly explained her experience:

What I want to tell you is that I have six children already. I gave three births before I started using contraceptive service and three after I started the use. I did so as I recognized that if I use a service I can plan when to become pregnant. Accordingly I have managed to postpone pregnancies after using the services. When you have space between pregnancies, you really love your children and become eager to see them. When you get rest between pregnancy means you get comfort both physically and mentally. You use your mind to think deeply how to overcome life challenges and set means to generate your own income. (FGD 06 Dis \#3 P. 40, para. 2, line 1-7)

Improvement in their marital relations was another area elucidated by the women who participated in the study. During the time when they were overwhelmed with many young babies and their related demands, the women frequently denied sharing linen with their husbands in bed. They said that thanks to the Lord and the government, they are now truly exercising their womanhood and feelings. When their bodies get adequate rest, and when they feel mentally free and at peace, not only do they please their husbands' desire, but also enjoy their own natural sexual desires.

A thirty year-old woman has elaborated experience of the issue:

With respect to sexual desire and feeling, I have no problem. Before contraceptive use I fear sexual relation with my husband for unwanted and mistimed pregnancy. Now nothing as such will frustrate me as I am able to protect unwanted pregnancy. We share all our feelings each other. I have a desire as a human being that has to be fulfilled. I feel joyful with regard to sexual intercourse this time. In order to satisfy each other, we discuss the sexual matter like any other household issue together. Contraceptive service has improved our health status. We better feed and take good care of ourselves in terms of hygiene and feeding. I have good feeling now as similar to the time I have married. (FGD 07 Dis\#3 P. 49, para. 1, line 1-7).

Some of the women who participated in the study have mentioned that they have been able to win back the heart of their husbands who had previously left them during their poverty and weakness. They are capable of attracting their husbands and catching their eye. Husbands who had left their overburdened wives now came back as they saw changes on their wives' appearances. Women expressed their deep feelings about the benefits of contraceptive use by indicating that they are really emancipated from the intrusions of unplanned pregnancies.

A discussant from FGD site 02 also elaborated the change in her marital relations and sexual life:

I reminded days back when I said no to sex to my husband. I think the reason for his new marriage was my unresponsiveness to his sexual request. The day came to me and now I face over feeling. So, where to get him? When he visits once every week, he understands that my feeling is highly improved. He says, you are really changed since started using contraceptive methods. He also says to, "now you are my best". I have better sexual desire than before and I need more but his absence from my home for a week discourages me. (FGD 02 Dis \#7 P. 18, para 7, line 9-16)

Another quote from a 30 year-old woman who used contraceptive service for eight years from FGD site 08 is presented below:

Before contraceptive service availability and its use, we hated male. We had no good environment to think about what sexual feeling is. As I said, we were not in position to care for ourselves and undermined our personhood. Therefore, we departed ourselves from our husbands. We lived in full of conflicting situation as our husbands urged to have sex but we denied their requests. As a result husbands were forced to look to other wives to feel their desire. The situation is now different. We use contraceptive service and share bedding with our husbands. We have no fear of unwanted pregnancy that hampers us from having sex. I am convinced to share my time with my husband in this affair. I don't want to annoy him and to hide my feeling this time like the previous time. (FGD 08 Dis \#7 P. 54, para. 5, line 1-9).

\section{Discussion}

\section{Why Contraception Matters to Health}

The perceptions of women regarding health-related experiences before contraceptive use, enabled the investigator to reflect on the previous professional observations and challenges concerning maternal and child health. During the early years of working in rural areas, the investigator experienced many prolonged and obstructed labours at the health center level with limited professional preparedness. When women were referred from the health center to the next possible hospitals, situated more than 100 
kilometers away with no means of transportation, women stayed home waiting for natural outcomes - often the death. It was evident that one of the effective methods to avert unplanned pregnancies (certainly end up on life loss), the contraceptive service, is barely existent.

In the study, women's experiences are examined before and after contraceptive use, with the results detailing differences in their health experienced after using contraception. The experiences revealed that women's health status before contraceptive use was generally poor. Failure to access contraceptive service, on the other hand, means devoid of the established health benefits of the services [27]. Women experienced very weak and dissatisfying livelihoods with subsequent poor health, illness, undernourishment, and unhygienic and disparate circumstances that further affected their wellbeing. Lack of access to modern contraceptive services adds to the prevailing conservative culture and patriarchal attitudes that affect women's health in many ways [28]. The women reported high child mortalities and morbidities, and unregulated fertility through closely spaced pregnancies and childbirths. Many children died before reaching their first birthday due to lack of proper care, and those who survived suffered from illness and under-nutrition. These results echo those of many other studies $[3,15]$.

In the study, the stories shared by the women when describing their lives following contraceptive use were very different than those preceding contraceptive use. Women's experiences following contraceptive use showed that first and foremost, they were able to control reproduction, and by extension their bodies, and thus exercise their human rights. Women identified contraceptive service as a miraculous gift from their Lord/God and the government. Contraceptive use enabled them to enact family planning and postpone unwanted/unplanned pregnancies. Their ability to plan pregnancies helped to improve their health status in many ways. Overall, frequent illness and hectic livelihoods have been gradually transformed into healthy and peaceful lives. "I have got peace and stability" is in fact, a profound statement. The experiences of the study women is in congruent with the study elsewhere and the reports of the world health organization and others organizations working in similar fields [28].

Contraceptive use has also contributed to the improvement of children's health status. When women space pregnancies they are able to provide proper care for their older children. Older children have enough time to feed on breast milk. When they reach the age for complementary feeding, a woman has more time and capacity to feed her child, unlike previous pre-contraception scenarios. Children also receive better health services. Contraceptive use created another beneficial opportunity for women to learn about aspects of child health such as vaccination and nutrition. As a result, children born to women using contraceptives receive vaccinations and grow well. Additionally, women are able to take their children to health institutions more easily, as they have increased time and awareness.

The women's experiences indicated that their lives were transformed following the use of contraception. They considered themselves most fortunate, as they were able to escape that dark time in which they lost many of their sisters and mothers prematurely due to complications during pregnancy and childbirth. High infant and child mortalities are not a matter of simple numbers for those families, and more importantly those mothers, who face it; it involves a loss of hope, feelings of great sorrow and of quarrelling with God [29]. Women, therefore, see themselves as most fortunate to experience this transformation in their lives at their ages.

\section{Conclusion and Recommendation}

This study was conducted with the broad aim of improving the overall understandings of health and social policy makers, health service providers, service users, researchers, and activists about women's perception of contraceptive use towards health and how these experiences would help in improving access and utilization of the service by the current non-user women. Rural women's experiences were examined in detail from the points of their life world; how they perceive contraceptive service use in relation to their health and that of their children.

Based on the study findings it can be concluded that in women's life worlds, the overall use of contraception has created remarkable means for women to control their bodies, their reproduction and their fertility. Contraceptive use has freed women from worries and traps related to unplanned and unwanted pregnancies and childbirths. It has opened wide opportunities for women; it has offered "peace and stability". The study witnessed that the health status of mothers and children have greatly improved. Premature deaths and sufferings were significantly reduced. Their visibility in the society and their marital relations are greatly improved. In that way, women would further accelerate the cascading of information to non-users by speaking more openly about contraceptive use and about women's position in society.

In order to ensure the continuous improvement of women's health and to establish sustainable contraceptive service organization; it is important to establish mechanisms to share the experiences of current service user women to the noneuser counter parts through the current service user women, the women development armies and a one-to-five networks.

\section{Appendix}

1. Transcription of focused group discussions, Sidama Zone, SNNPR, Ethiopia.

2. Transcription of individual in-depth interview, Sidama Zone, SNNPR, Ethiopi.

\section{References}

[1] Alemayehu, T., Haidar, J. \& Habte, D. (2009). Determinates of exclusive breast feeding practice in Ethiopia. Ethiopian Journal of Health Development, 23 (1). 
[2] Habtom K Gebremichael. (2017). Factors affecting the use of maternal and child health in Eritrea, Journal of complementary medicine and Alternative health care, 2 (3).

[3] Gaym, A. (2009). Maternal mortality studies in Ethiopiamagnitude, causes and trends, Ethiopian Medical Journal, 47 (2), 95-108.

[4] Darroch, J. E., Singh, S., \& Nadeau, J. (2008). Contraception: an investment in lives, health and development. In: In Brief (No. 5). New York: Guttmacher Institute and UNFPA.

[5] Bongaarts, J. Cleland, J., Townsend, J., W., Bertrand, J. T., and Gupta, M. D. (2012). Family planning program for the $21^{\text {st }}$ century. Rationale and design. Population Council, New York, USA.

[6] McGinnis, K. (2011). Decreasing unwanted pregnancies by increasing use of emergency contraceptive pills (ECPs): A leadership approach. Florida Public Health Review, 8, 25-30.

[7] Rutstein S. O. (2008). Further evidence of the effects of preceding births intervals on neonatal, infant and under-five years' mortality and nutritional status in developing countries: evidence from the demographic and health surveys. DHS Working Paper. Calverton, MD, USA: Macro International. 41 .

[8] Smith, R., Ashford, 1., Gribble, J., \& Clifton, D. (2009). Family Planning Saves Lives $\left(4^{\text {th }}\right.$ ed. Population Reference Bureau, at $5, \quad$ available at http://www.prb.org/Reports/2009/fpsl.aspx

[9] Peipert J et al., (2012). Preventing unintended pregnancies by providing no-cost contraception, Obstetrics \& Gynecology, $120(6), 1291-1297$.

[10] Nelson, A., \& Rezvan, A. A. (2012). Pilot study of women's knowledge of pregnancy health risks: implications for contraception, Contraception, 85 (1), 78-82.

[11] Conde-Agudelo, A., Rosas-Bermúdez, A., \& Kafury-Goeta, A. C. (2006). "Birth spacing and risk of adverse perinatal outcomes: A meta-analysis," Journal of the American Medical Association 295 (15): 1809-1823.

[12] Cleland, J, Bernstein, S., Ezeh, A, Faundes, A., Glasier, A., \& Innis, J. (2006). Family planning: The unfinished agenda. Lancet 368, 1810-1827.

[13] United States Aid for International Development (USAID), (2010). Women's sexual and reproductive health rights in Ethiopia: The role of National Government and US foreign assistance.

[14] Guttmacher (2010). Facts on Investing in Family Planning and Maternal and Newborn Health. In Brief. Washington, DC: Guttmacher Institute.
[15] Central Statistical Authority (CSA) \& ORC Macro. (2011). Ethiopia Demographic and Health Survey. Addis Abab: CSA.

[16] Central Statistical Authority of Ethiopia (CSA, E). (2007). Population census.

[17] Sidama Zone Health Department (2012). Sidama Zonal health profile. (unpublished).

[18] Flood, A. (2010). Understanding phenomenology. Nursing research, 17 (2), 7-15.

[19] Munhall, P. L. (2012). Nursing research. A Qualitative perspective. Fifth edition. Jones \& Bartlet Learning. Miam, Filorida.

[20] van Manen, M. (1997). Researching lived experience: Human science for an action sensitive pedagogy (2nd ed.). London, Ontario, Canada: Althouse Press.

[21] Krueger, R. A., \& Casey, M. A. (2009). Focus groups: A practical guide for applied research (4th Ed.). Thousand Oaks, CA: Sage Publications.

[22] Wojnar, D. M. \& Swanson, K. M. (2007). Phenomenology: an exploration. Journal of holistic nursing, 25 (3), 172-180.

[23] Curtin, M. \& Fossey, E. (2007). Appraising the trustworthiness of qualitative studies: guidelines for occupational therapists. Australian occupational therapy journal, 54 (2), 88-94.

[24] Rolfe, G. (2006). Validity, trustworthiness and rigour: quality and the idea of qualitative research. Journal of advanced nursing, 53 (3), 304-10.

[25] Morrow, S. L. (2005). Quality and trustworthiness in qualitative research in counseling psychology. Journal of counseling psychology, 52 (2), 250-260.

[26] Bailey, M. J., (2006). More power to the pill: the impact of contraceptive freedom on women's life cycle labor supply. The Quarterly Journal of Economics. 121 (1): 289-320.

[27] Lassi, Z. S., Salam, R. A., Das, J. K. \& Bhutta, Z. (2014). Essential interventon for maternal, neonatal and child health: background and methodology. Reproductive Health Journal, $11(1), 1-7$.

[28] Minkovitz, C. S., Chen, Yi-Hua, \& Grason, H. A. (2002). Association between maternal and child health status and patterns of medical care use. Ambulatory Pediatrics, 2, 85-92.

[29] Karacam, Z., Onel, K. \& Gercek, E. (2011). Effect of unplanned pregnancy on maternal health in Turkey. Midwifery, 27 (2), 288-293. 